\author{
Marek Vaculík \\ Moravian University College Olomouc \\ Crech Republic \\ Faculty of Business Economics, Hasselt University \\ Belgium \\ Marek.Vaculik@o-k-i.cr.
}

\title{
Vít Pászto
}

Department of Geoinformatics, Palacký University Olomouc

Czech Republic

vit.paszto@upol.cz.

\section{Barbora Švarcová}

Department of Geoinformatics, Palacký University Olomouc

Czech Republic

zdenka.svarcova@upol.cz.

Abstract. Innovation is widely considered as an engine of economic growth, competitiveness and job creation. As such it has become a hot policy topic over the last years, especially on regional and national levels. Thus, it is vital to analyze and evaluate innovation activities, whether they are dispersed or concentrated in space. This article address the question: are innovations spatially clustered or not? In this article, we obtain a clear picture of the geographical distribution of innovation activities carried out by companies in Czech Republic during 20102012. Visual and statistical analysis of firm-level survey data concerning innovation activities of 5,449 (22\% of the statistical population) Czech companies has been performed. Using four newly calculated innovation measures, their overall scores in Local Administrative Units 1 and consequent geovisualization allowed us revealing clusters of innovating districts and evaluating their spatial patterns. The main findings are that low innovative regions are located mainly (1) in the borderlands, (2) in rural areas, and (3) in mountainous areas. On the other hand, highly innovative regions tend to be in major cities and their neighborhoods, which indicates a positive spillover effect.

Keywords: innovation activity, geographical distribution, Czech Republic, spatial concentration, high-innovative companies war.

JEL Classification: O31, R12 


\section{INTRODUCTION}

When characterizing nowadays market economy, we frequently use adjectives such as "turbulent", "dynamic", "disruptive", "unpredictable" and so on. All of these labels have one thing in common; they reflect a dominant feature of our times - rapidly changing business environment. There are many factors causing this: technological advances, unconstrained financial flows, increasing number and mobility of knowledge-intensive workers, changing customer's preferences among the most prominent ones. In order to be able to cope with these environmental frictions, companies have to be active in new product development, exploration of new business opportunities and out-of-the-firm's-boundaries-knowledge-exploration. These activities are then enhancing the innovation process and/or experimentation, both being vital for maintaining the competitive advantage. Due to innovation activities, managers are not at the mercy of external events, but they are empowered to influence and cultivate actively their environment. Innovation is undisputedly considered as the key to growth and long-term success.

The nature of innovation research is very broad, and the research results are inconsistent due to the lack of generalizability of innovation studies (Wolfe, 1994). We should, therefore, differentiate among various types and attributes of innovation. As regards different types of innovation we can find in literature an enormous number of distinctions such as incremental vs. radical (Ettlie et al., 1984), technical vs. nontechnical (OECD, 2005) or autonomous vs. systemic (Chesbrough \& Teece, 1996). As with types, there are many ways how to measure innovation activity. In the case of technological innovation Carlino \& Kerr (2014) show three possibilities: (1) by the inputs used in the innovation process (e.g., R\&D expenditures, VC funding), (2) by intermediate outputs of innovation efforts (e.g., the number of patents) or (3) a final measure of innovative activity such as a new product.

There is a vast body of literature examining the organizational context of innovation studying the best set of organizational structure, properties and factors enabling innovative processes either on the level of individual firm (Damanpour, 1991; Koberg et al., 2003; Ernst, 2002) or on the industry level (Hrebiniak \& Joyce, 1985; Audretsch, 1995). At the same time, spatial distribution of industries has been a focus of many studies as well (Ellison \& Glaeser, 1997; Prevenzer, 1997; Venables, 1996). We are interested in both issues of innovation activity and spatial concentration, for which we investigate the geographical distribution of innovation activities. Studies examining such spatial distribution of innovation activities are rare (Fornahl \& Brenner, 2009). Methods and techniques for analyzing economic data with a spatial component in a quantitative way are being named as spatial econometrics. Basic concepts of spatial econometrics are described to a great extent in Anselin (1988), Pace \& LeSage (2009), Paelinck \& Klaassen (1979).

The aim of our paper is to consider whether high-performing innovative companies are geographically concentrated, following any spatial pattern, or not at all. We analyze the spatial distribution of innovation activities of Czech firms using anonymous firm-level data from cross-sectional Community Innovation Survey 2010-2012 (CIS, 2012). From the geospatial point of view, it is always necessary to display data via maps in order to explore basic geographical characteristics of the mapped phenomenon. According to de Smith, Goodchild and Longley (2015), maps have been the primary means to store and communicate spatial data. Objects (firms) and their attributes (innovation measures) can be readily depicted, and the human eye can quickly discern patterns and anomalies in a well-designed map (de Smith, Goodchild, \& Longley 2015). In case of this paper, geovisualization of firms' innovations aggregated into districts (Local Administrative Unit 1 - LAU1) of Czech Republic was used. Nevertheless, calculations of particular innovation activities needed to be done beforehand. The presented here geovisualizations thus demonstrate the selected results of innovations performed by firms. 
This article is structured as follows: we begin our study by reviewing literature concerning various aspects of innovation activities and their spatial distribution. Next we follow with a discussion of our research design, and our results. In the last section we highlight the theoretical implications of our findings, also discussing the study's main limitations, and suggest the course for future research.

\section{THEORETICAL BACKGROUND}

In this section, we review the theoretical basis supporting the hypotheses that high-performing innovative firms tend to be concentrated in geographic and industrial clusters rather than being isolated. Based on the literature we present main forces and factors leading to the agglomeration of innovative activities.

\section{Industry clusters}

The idea of the benefits of industry clustering embodied mainly in positive agglomeration externalities serving as a catalyst for economic growth has been around for a very long time (Marshall 1920). There are many examples of that phenomenon e.g. Silicon Valley for IT technology, London City and Wall Street for financial services and even Hollywood for a film industry. In some cases, the geography itself presents obvious natural advantages that result in cluster formation. That is mainly a case of primary sector of the economy including agriculture, fishing, mining and forestry.

There exist a plenty of different forces and factors which give rise to a spatial concentration of industrial activity. Companies with similar competencies and needs or complementary interests tend to congregate around each other. The other strong motivation is cost-effectiveness as the geographical proximity lowers the cost of transporting goods, people and ideas too. Reduction of transportation costs is evident as it stems from the co-location of customers and suppliers. Porter (1998) indicates that the possibility of local outsourcing enables companies to reduce production costs by maintaining leaner inventories.

When firms locate in a cluster, firms can benefit from a pool of skilled workers and expertise, making it easier to hire new workers when labor demand increases and facilitating better matching of workers to jobs (Berliant et al. 2006). The agglomeration also makes easier access to various ancillary services which in turn lower the costs even further.

The presence of strong industrial clusters also delivers advantages for regional development. Literature indicates that areas with strong clusters produce more economic growth (Krugman 1991), more jobs and stronger wage growth (Wennberg \& Lindquist 2010), increased entrepreneurial activity (Kuechle, 2014), and more intellectual property—such as patents— than other areas (Carlino et al. 2007).

\section{Knowledge spillovers}

One of the most important and discussed effects of agglomeration are knowledge spillovers. We can define knowledge spillovers as a certain form of non-market interaction in the form of externalities where the technical, scientific or market information becomes some kind of a public good (positive external effects). These interactions are decreasing significantly with increasing spatial distances among the specific knowledge sources and companies. It means that when companies are in proximity to each other, to competitors, suppliers and especially to scientific centers such as universities, RD labs, etc. the informal exchange of ideas is more likely (Freeman, 1991). And that this proximity can facilitate the spread of tacit knowledge and information sharing. 
Tacit knowledge is not easily codified and interpreted; it is locally bounded so that there is a need for regular face-to-face interactions and a certain level of trust to be able to share it. On the other hand, it is the tacit knowledge rather than common information which is crucial for any breakthrough innovation. Due to the nature of tacit knowledge, the possibility of its sharing is a function of the distance as knowledge spillovers operate at the smallest spatial scales (Carlino \& Kerr 2014), and their effects rapidly decay with distance (Henderson 2007). These findings also have an important connection to the concentration of innovative activities as they imply that companies operating in specific industry domains are located near each other and close to universities and scientific centers in order to have access to new knowledge.

\section{Public policy - supporting measures}

Innovation has become a hot policy topic over the last years. Nowadays the innovation is said to be a key to increasing the economic growth, sustain competitiveness and create new jobs. That is why the decision-makers got actively involved in the design and implementation process of various innovation support systems on regional, national and even EU level (Ďuricová, 2015).

There are many initiatives to encourage development and concentration of innovation, attempts to improve innovative capacity of companies such as measures to assist the transfer and utilization of technology, increasing the human resources competence, etc. Behind these efforts, there is a broader aim of improving the competitiveness of the whole economy. The question is how effective (in economic terms) these measures are and on what assumptions and evidence are they based.

It is perhaps a dream of every policymaker to "create" a next Silicon Valley. But as the empirical evidence shows (Chatterji, et al. 2014) the problem of creating the whole ecosystems underlying clusters of innovation is too complex for any targeted policy interventions. Rather the policymakers should focus on measures aimed at enabling an environment for innovation such as flexible labor market policies, highquality education systems, functioning infrastructure, $R \& D$ tax cuts and most importantly easing the administrative and regulatory barriers to entrepreneurial activities.

\section{DATA AND METHODS}

\section{Data}

We use the results of the sixth round of the Community Innovation Survey held in 2013 for the Czech Republic on data from 2010-2012 (CIS 2012). As the CIS is conducted every three years, its $6^{\text {th }}$ round is to date of this paper the most recent one for exploring innovation activities on national level. The CIS 2012 uses harmonized questionnaire for all EU member states and as such presents unique and reliable source of data regarding innovation activities of enterprises of different size, age, and industry. The huge advantage of the CIS 2012 is the long-term experience with methodological issues related to the innovation activities using revised version of the Oslo Manual 2005, involving data on technical types of innovation (product and process) as well as on the long underestimated findings on non-technical innovations (marketing and organizational). At the same time, it has gained external validity because the same questionnaire has been used in most European countries.

Data for CIS 2012 were gathered in 2013 by questionnaire sent to all enterprises with ten or more employees, stratified by size and economic activity. The survey cover manufacturing as well as service firms. In total 5,449 responses were received with $80 \%$ rate of useful answers. 
The main constraint of using CIS, as highlighted by Armbuster et al. (2008), regards the three years time lag which can lead to incorrect results. Different types of innovation activity can have different lifecycles and enterprises might benefit from them for more than three years so that the firms introducing the innovation earlier are supposed here to be non-innovators. Anyway, this is not a case on a larger scale and for a majority of innovative actions, the three years time-span provides sufficient time to cover the internal and external changes and their impact on other activities of a firm.

From a geospatial perspective, it is always beneficiary having data at the most detailed level in the sense of geographical scale. Although the CIS survey is realized at the firm-level, the resulting data set is anonymized. Thus, it is not possible to identify an individual subject for its accurate localization. Besides, Czech Statistical Office offers data at the LAU1 level, because 5,449 respondents would be very sparsely dispersed throughout the Czech Republic when displayed at firms' original locations. Nevertheless, there are 77 LAU1 districts in the Czech Republic and all of them are represented in the CIS 2012 dataset.

\section{Measures}

As we want to obtain a full picture of the innovation activity of Czech firms we use four different types of measures which belong to two broader groups of innovation measures. The first one relates to the investments in the innovation process and is measured by the inputs utilized in the innovation process (in our case R\&D investments). The second group of measures focuses on the final output of the innovative work e.g. new products and/or processes introduced.

\section{a) Technical innovation}

Technical innovation is a composite binary variable merging information on product and process innovations. In CIS 2012 the product innovation is the market introduction of a new or significantly improved good or service with respect to its capabilities, user-friendliness, components or sub-systems. It must be new to the respondent but not necessarily to their market. The process innovation, on the other hand, is the implementation of a new or significantly improved production process, distribution method, or supporting activity.

\section{b) Non-technical innovation}

This measure is again a composite binary variable consisting of organizational and marketing innovations. The organizational innovation is a new organizational method in respondents' business practices (including knowledge management), workplace organization or external relations that have not been previously used. It must be the result of strategic decisions taken by management excluding mergers and acquisitions. The marketing innovation is the implementation of a new marketing concept or strategy that differs significantly from respondent' existing marketing methods and which has not been used before. It requires significant changes in product design or packaging, product placement, product promotion or pricing excluding seasonal, regular and other routine changes in market methods.

\section{c) Radical innovation}

Radical innovation is a binary variable referring to a new or significantly improved product (good or service) introduced during 2010-2012 which was new-to-the-market (it may have already been available in other markets). Radical or sometimes called disruptive innovation encompass higher order innovations that 
have an enormous market potential, and that comprise technological advances so significant that no increase in scale, efficiency, or design can make older technologies competitive (Tushman \& Anderson, 1986). In our context, we use this measure as a clear indicator of highly innovative activities of a firm.

\section{d) R\&D intensity}

The extent or better say the intensity of $\mathrm{R} \& \mathrm{D}$ activities is shown as a crucial measure of innovativeness of individual companies. Many studies demonstrated a clear positive impact of these activities on business performance measured as the number of new products to market and financial terms. We calculated the variable as a proportion of total R\&D costs on turnover of the companies within districts in 2012.

\section{Methods}

In this paper, we predominantly use descriptive statistics in combination with basic geospatial methods. We use visualization techniques provided by the ArcGIS for Desktop 10.x software. Firstly, it was necessary to prepare the dataset with calculated measures. We have created four different variables representing the innovation activity of firms in Czech Republic. The variables are described above as "innovation measures", with the information how they were calculated. For descriptive statistics please see the table 1 . It shows the mean score, the standard deviation and the minimum and maximum scores. The statistics show that onequarter (25.6\%) of firms has introduced technical innovation between 2010 and 2012. Combined with those introducing non-technical innovation $(15.7 \%)$ we can see that majority of firms $(58.7 \%)$ have not introduced any innovation between 2010 and 2012. It is not surprising that minority of new products and processes is radical $(19.6 \%)$ on the other hand the intensity of research and development activities is quite impressive with the score above $12 \%$.

Table 1

Descriptive statistics of variables used as innovation measures

\begin{tabular}{|l|c|c|c|c|}
\hline \multicolumn{1}{|c|}{ VARIABLES } & mean & sd & min & max \\
\hline & & & & \\
\hline Technical innovation & 0.256 & 0.436 & 0 & 1 \\
\hline Non-technical innovation & 0.157 & 0.364 & 0 & 1 \\
\hline Radical innovation & 0.196 & 0.397 & 0 & 1 \\
\hline R\&D intensity & 0.122 & 0.327 & 0 & 1,62 \\
\hline
\end{tabular}

Consequently we joined the measures with the spatial information (LAU1 graphical layer). Since both non-graphical (table with measures) and graphical (spatial representation of LAU1 districts) parts of the data contain the unique LAU1 codes, it was possible to join them together. Once we had joined data available in GIS (Geographical Information System) software, the next step was to explore the spatial distribution of firms' innovations via maps. In addition to visualizations themselves, geographic distribution was measured using standard deviation ellipse. This method measures the trend for a set of points or areas by calculating the standard distance separately in the $\mathrm{x}$ - and $\mathrm{y}$-directions (for more details see Ebdon, 1988 or Mitchell, 2005). The ellipse allows us to see if the distribution of features is elongated and hence has a particular orientation (Mitchell, 2005).

Our approach for overall innovation evaluation stems from a method used originally by Adams (2011) for determining the distribution of innovation activity in the UK. The concentration of innovative activities 
is determined by proportions at the level of LAU1 district. First, scores $S$ for each LAU1 district (i) across a range $q=\{a, b, c, d\}$ of abovementioned innovation measures $(q)$, are calculated as follows:

$$
S_{i q}=\frac{I_{i q}}{R_{i}}
$$

Where for each LAU1 district $I_{i q}$ is the number of companies from LAU1 district $i$ registering any level of activity in innovation measure $q$, and $R_{i}$ is the total number of respondents $R$ from given LAU1 district $i$.

Then the scores $S_{i q}$ are ranked, the LAU1 districts that comprise the upper decile of each innovation measure can be identified. So, districts with concentrated innovative activity are those that appear at the top of a list of rankings which are based on the proportions of respondents active in a series of innovation measures on the total number of respondents in a given district. Each time a LAU1 district appears in upper decile of the innovation measure rankings receives one point. The final ranking of LAU1 districts is made in order to see whether there are any LAU1 districts consistently appearing in the upper decile of innovation measures.

Resulting map with final ranking points is complemented by four maps showing sub-ranking highlighting upper decile of individual measures. Furthermore, the final ranking points map contains basemap showing the overall ratio of firms' innovations in a LAU1 district and a total number of respondents.

\section{RESULTS}

Since the major output of this paper is geovisualization of firms' innovation activities, the results will be discussed in this manner. Individual measures are displayed in Figure 1, where only those LAU1 districts ranked in upper decile are depicted. At first glance, there is no distinct pattern of innovations' spatial concentration. Ideally, high-performing LAU1 districts (those in the first decile of the ranking) would be grouped into one or two spatial clusters. The two-member cluster was formed only in three cases - nontechnical innovation, radical innovation and $R \& D$ intensity measure (one cluster per each measure). Therefore, it is necessary visually analyze and evaluate the measures individually at more detailed level.

When looking at technical innovations, it can be seen in which LAU1 districts the most of these innovations took place. Nevertheless, there are no adjacent $1^{\text {st }}$ decile-ranked districts. It is quite hard to find the link between technical innovation and space/place. Five districts lie in a neighborhood of the major cities (Prague, Brno, Liberec, Zlín and Ostrava), so potentially the technical innovations are tied with the agglomerations. Any of the traditional industrial regions is included in the $1^{\text {st }}$ decile. Thus, it is supposed that high ratio of technical innovations is the result of piled-up firms multiplication effect.

Regarding the non-technical innovation, there is one cluster formed on the west of the country. It interesting to see, that the majority of the $1^{\text {st }}$ decile districts in this category are located in the borderlands, which are formed mainly by the rural type of the landscape. From this point of view, it seems that greatest amount of non-technical activities were carried out in the rural border regions (of course with some exceptions, e.g. district in the very northeast part of the Czech Republic, which is an urban area). 

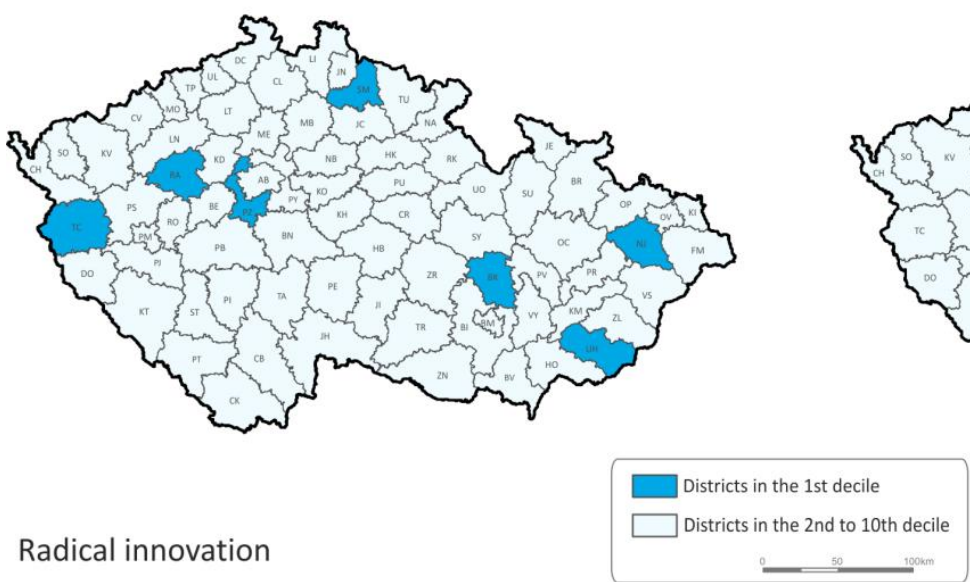

Radical innovation
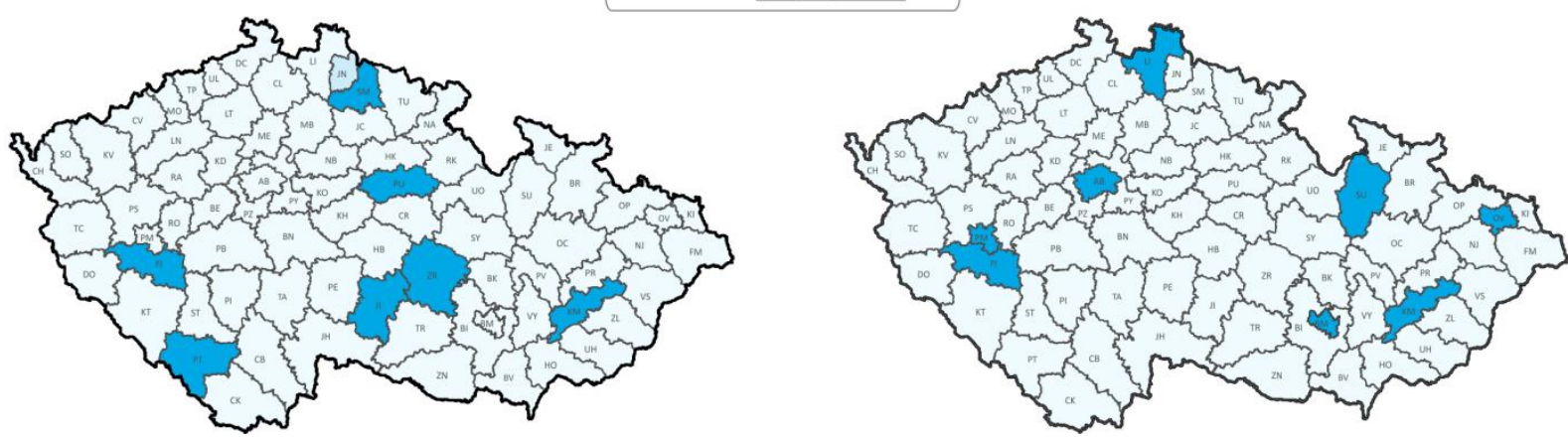

Figure 1. Spatial distribution of LAU1 districts ranked in the upper decile according to individual measures

Radical innovations represent new or significantly improved product which are new-to-the-market. From the geospatial point of view, districts with highest scores in this measure are located outside the most populated regions, but some of them in the regions with county major cities (i.e. Pilsen, Liberec, Pardubice, Jihlava). There are districts with proximity to major cities and districts lying in rural areas as well; or its combination, i.e. districts in proximity of larger cities and being rural at the same time (for instance Plzeňjih). In other words, radical innovations took place outside the largest cities, but in districts that are still regionally connected to them. It is a question, whether the firms in these districts are striving to introduce a greater amount of radical innovations in order to increase their competitiveness, or the reason is completely different.

Finally, the spatial configuration of districts in the $1^{\text {st }}$ decile of R\&D intensity measure confirms to some extent the assumption of very close research cooperation between firms and local universities. All four biggest cities, namely Prague, Brno, Ostrava, and Plzeň, are ranked to be in the 1 st decile of the R\&D intensity. Nevertheless, there are districts with a high ratio of $\mathrm{R} \& \mathrm{D}$ in more or less rural regions (both in inner-periphery and borderlands).

Overall spatial distribution of innovation activities intensity is depicted in Figure 2. The map shows a total number of points per districts ranked in upper decile. It represents a synthesis of maps in Figure 1, which allows identifying regions with clustered districts by the innovation. As the individual measures were spatially dispersed throughout the Czech Republic, consequently the maximum innovation score were two points - meaning that LAU1 district appeared in the $1^{\text {st }}$ decile only twice. . 
The spatial trend was evaluated by the standard deviation ellipse, whichspatially delimits features (in this case LAU1 districts) by the standard deviation of their location. In other words, LAU1 districts outside the ellipse tend to have no spatial relationship with those within the ellipse. This may be interpreted as a "service area" of innovations' diffusion. The similar interpretation could be made for all groups of LAU1 districts. There should be noted that standard deviation ellipses could be calculated for at least three features (districts). From Figure 2, it is evident, how highly-innovating districts are spread across the country with three main clustered regions. Standard deviation ellipses highlight those regions. The first one is located western from Prague with the virtual center in Rakovník district. Districts containing Prague and Plzeň, as the biggest cities in this region, are included in this group. The second group of districts reaching the $1^{\text {st }}$ decile at least once is in the southeastern part of the Czech Republic around the city of Brno. The significant amount of innovations was carried out in districts around Ostrava (the third identified group). Although this region has been over a long period affected by structural economic problems (e.g. unemployment) due to a heavy industrial orientation, innovations seem to be an important feature of its economy. The rest of the districts in the Czech Republic did not form an innovative region. Geographically, low innovative regions (those with no district ranked in upper decile) are located mainly, with some exceptions, (1) in the borderlands, (2) in rural areas, and (3) in mountainous areas.

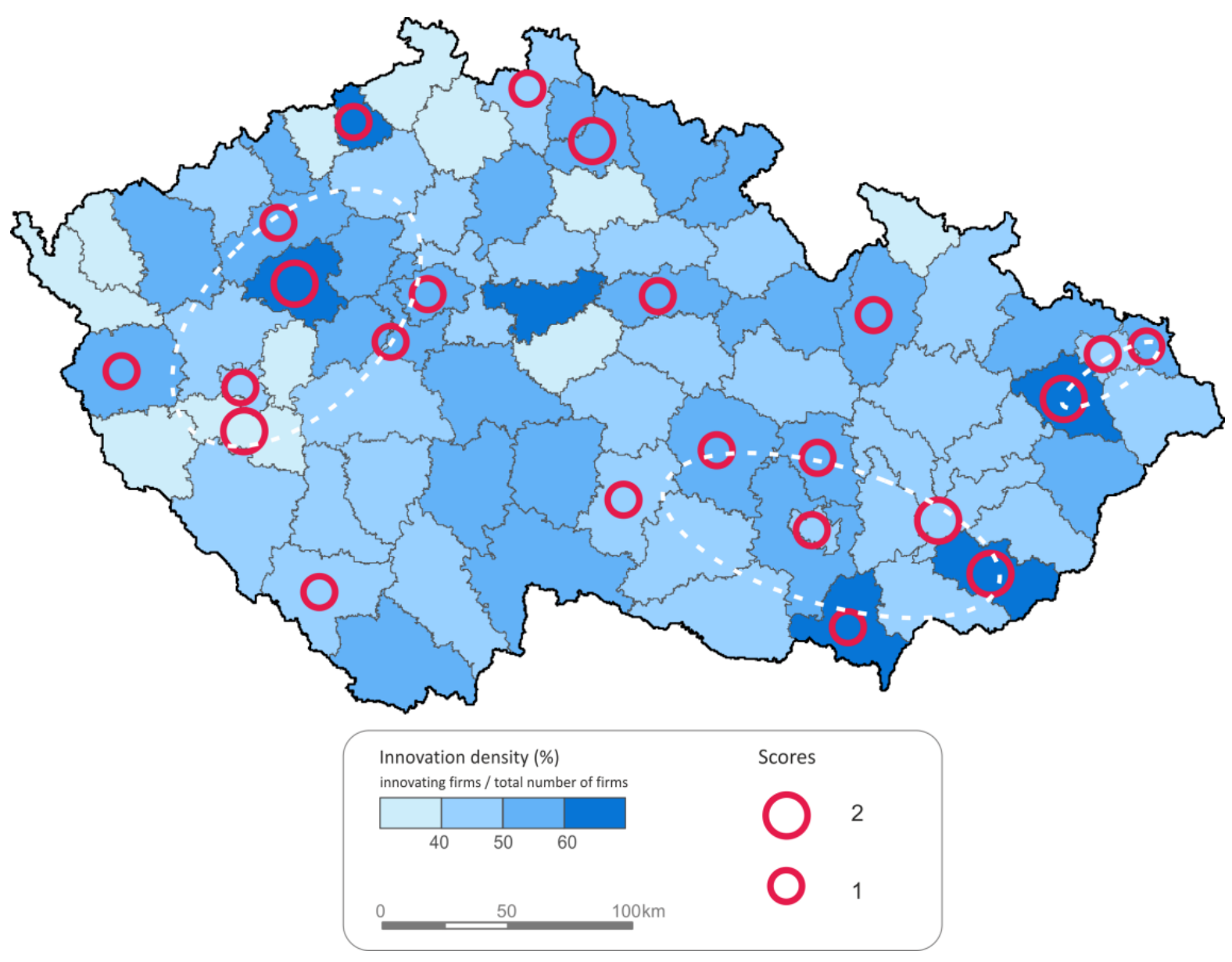

Figure 2. Intensity of innovation activities in LAU1 districts 
As a basemap (underlying choropleth map), innovation density was calculated and depicted. Innovation density is expressed as the percentage of innovating firms and a total number of firms (respondents). It is interesting that 5 of 23 districts with scores at least one point have more than $60 \%$ innovation density ratio. Only one district, Kolín, with the ratio of $60 \%$ and more of innovating firms was not ranked in the $1^{\text {st }}$ decile (therefore not being scored). For the rest 18 districts (including the latter one), it means that lower number of firms introduced a significant number of innovations. Nevertheless, districts with high innovation density ratio appear to be highly innovative but not ranked into upper decile. Despite the fact that the most of the surveyed firms reported some kind of innovation in the district, any of it was of great significance. Generally, the worst scenario is the combination of low innovation density and zero scores. Again, the lowest ratio of innovation density is present in LAU1 districts that are (1) in the borderland (especially western part of the Czech Republic), (2) in rural areas, and (3) mountainous areas. Obviously, there are some exceptions, but these are geographically more or less isolated.

\section{DISCUSSION}

The aim of this article has been to explore the spatial distribution of innovation activities and the intensity of research and development investments. Particularly, we wanted to investigate whether the highperforming innovative companies are geographically concentrated, following any spatial pattern, or not at all. To do so we analyzed the spatial distribution of innovation activities of Czech firms using anonymous firm-level data from cross-sectional CIS 2012.

As results of our analyses reveal, there is a clear pattern of spatial concentration of innovation activities which are mainly co-located around the biggest Czech cities. Geographically, low innovative regions are located mainly (1) in the borderlands, (2) in rural areas, and (3) in mountainous areas. Especially in the case of inner rural peripheries and borederlands, the innovation (in)activity is related with overall problematic socio-economic situation in these regions, which corresponds with findings from recent studies on the rural areas (e.g. Pászto, et al., 2016; Perlín, Kučerová \& Kučera, 2010).

These findings are complementary to prior studies on industrial clusters (Ellison \& Glaeser 1997; Audretsch, 1998) that focus mainly on the factors and benefits of agglomeration of industrial sectors, both manufacturing and services. Our empirical results enrich the industrial cluster perspective by involving the innovation activities and vice versa broaden the scope of innovation literature by taking into account the underlying forces of agglomeration of industrial activity, including spatial aspects. In our work we show that both industrial activity and innovation activity follow the same pattern of concentration so that there is a high probability that both of these phenomena are mutually interdependent and influenced by the same forces and factors.

The implications of our findings are dealing mainly with regional development policymaking. As it seems there should be a more targeted approach in supporting innovation activities mainly in the regions on periphery. The support should aim at strengthening ties among various enterprises and knowledge centers in order to extend the spillover effects to areas further from the industrial clusters and knowledge centers.

In this direction our research has also a clear value on the European level as the support of structurally weaker regions is at the cornerstone of the EU. We can argue that due to the massive resources poured in the regional development during the last decade we foresee more innovation activities in peripheral regions and more dense ties between industrial clusters and less-developed areas. 
Future research avenues should deal with space-time analysis between two adjacent periods of the CIS survey. Furthermore, advanced spatial statistical tools (e.g. spatial clustering, local indicators of spatial association, spatial correlation, etc.) could be applied to describe the datasets more quantitatively. It would also be interesting to find out relations with other types of data available (e.g. demographic, macroeconomic, (un)employment data and so forth) in order to be able to explain in more detail the various forces of a concentration of industrial as well as innovation activities. There is also a room for assessing the effectiveness of the EU regional development policies and measures which are aimed at boosting innovation and growth in weaker regions. Further research could tap into that issue by comparing data on innovation activities before the support from EU structural funds with recent situation.

There are also some limitations. Due to the nature of CIS survey methodology (e.g. randomly selected sample, reliability of answers, firms ID anonymization), it is obvious that there is some degree of uncertainty in data. Nevertheless, the bias needs to be accepted since there is no other effective/realistic way how to obtain this kind of data. The sample of 5,449 firms answering the survey is sufficient enough for any meaningful quantitative analyses.

\section{CONCLUSION}

This article addresses spatial distribution of innovative activities in the Czech Republic in 2010-2012. Building on the industrial cluster, innovation, and knowledge spillover literature, this study developed and tested a model investigating the patterns of concentration of innovation activities within agglomeration centers. As the enabling environment for innovation and industrial activities is a very hot topic especially among policymakers, we see abundant possibilities for further research. There is a vast body of literature dealing with innovation alone without insights from the industrial cluster perspective, and spatial aspects. Based on our results, we see an opportunity in closer cooperation between these theoretical approaches in order to explore the underlying factors enhancing both phenomena.

\section{REFERENCES}

Adams, R. (2011). The distribution of innovation activity across UK industry: final report. University of Exeter, Department of Business, Innovation and Skills.

Anselin, L. (1988). Spatial Econometrics: Methods and Models. Kluwer Academic, Dordrecht.

Armbuster, H., Bikfalvi, A., Kinkel, S., \& Lay, G. (2008). Organizational Innovation: The Challenge of Measuring Non-Technical Innovation in Large-Scale Surveys. Technovation, 28, 644-657.

Audretsch, D. (1995). Innovation and Industry Evolution. Cambridge, MA, MIT Press.

Audretsch, D. (1998). Agglomeration and the Location of Innovative Activity. Oxford Review of Economic Policy, 14(2), 18-29.

Beaudry, C., \& Breschi, S. (2000). Does “Clustering” Really Help Firms' Innovative Activities?, Working Paper-Manchester Business School.

Berliant, M., Reed, R., \& Wang, P., (2006). Knowledge exchange, matching, and agglomeration. Journal of Urban Economics, 60(1), 69-95.

Carlino, G., Chatterjee, S., \& Hunt, R., (2007). Urban density and the rate of invention. Journal of Urban Economics, 61(3), 389-419.

Carlino, G., \& Kerr, W.R. (2014). Agglomeration and Innovation. Working Paper, 15-007, Harvard Business School.

Chatterji, A., Glaeser, F., \& Kerr, W. (2014). Clusters of entrepreneurship and innovation. In: Lerner, J., Stern, S. (eds.), Innovation policy and the economy, 14, 129-166.

Chesbrough, H.W., Teece, D.J. (1996). When Is Virtual Virtuous? Organizing for Innovation. Harvard Business Review, 74(1), 65-73. 
Damanpour, F. (1991). Organizational Innovation: A Meta-Analysis of Effects of Determinants and Moderators. The Academy of Management Journal, 34(3), 555-599.

De Smith, M. J., Goodchild, M. F., Longley, P. (2015). Geospatial analysis: a comprehensive guide to principles, techniques and software tools. Troubador Publishing Ltd.

Duricová, V. (2015). Factors affecting innovation activities of firms in the EU countries. Economics, Management, Innovation, 7(3), 83-92.

Ebdon, D. (1988). Statistics in Geography (2nd ed. with corrections). Oxford, UK: Blackwell.

Ellison, G., \& Glaeser, E. (1997). Geographic Concentration in US Manufacturing Industries: A Dartboard Approach, Journal of Political Economy, 4, 889-927.

Ernst, H. (2002). Success Factors of New Product Development: A Review of the Empirical Literature. International Journal of Management Reviews, 4(1), pp. 1-40.

Ettlie, J.E., Bridges, W.P., \& O’Keefe, R.D. (1984). Organization Strategy and Structural Differences for Radical Versus Incremental Innovation. Management Science, 30(6), 682-695.

Fornahl, D., \& Brenner, T. (2009). Geographic Concentration of Innovative Activities in Germany. Structural Change and Economic Dynamics, 20, 163-182.

Freeman, C. (1991). Networks of Innovators: A Synthesis of Research Issues. Research Policy, 20, 499-514.

Henderson, J.V. (2007). Understanding Knowledge Spillovers. Regional Science and Urban Economics, 37(4), 497-508.

Hrebiniak, L.G., \& Joyce, W.F. (1985). Organizational adaptation: strategic choice and environmental determinism, Administrative Science Quarterly Vol. 30, (3), pp. 336-349.

Koberg, Ch.S., Detienne, D.R., Heppard, K.A., (2003), An Empirical Test of Environmental, Organizational, and Process Factors Affecting Incremental and Radical Innovation. The Journal of High Technology Management Research, 14(1), 21-45.

Krugman, P. (1991). Increasing Returns and Economic Geography. Journal of Political Economy, 99(3), 483-499.

Kuechle, G. (2014). Regional Concentration of Entrepreneurial Activities. Journal of Economic Behavior and Organization, 102, 59-73.

Marshall, A. (1920). Principles of Economics, $8^{\text {th }} \mathrm{ed}$. Macmillan, London.

Mitchell, A. (2005). The ESRI Guide to GIS Analysis, 2. ESRI Press.

OECD. (2005). Oslo Manual: Guidelines for Collecting and Interpreting Innovation Data, $3^{\text {rd }}$ edition.

Pace, R. K., \& LeSage, J. P. (2009). Introduction to spatial econometrics. Boca Raton, FL: Chapman\&Hall/CRC.

Paelinck, J. H. P., \& Klaassen, L. L. H. (1979). Spatial econometrics (Vol. 1). Saxon House.

Pászto, V., Burian, J., Marek, L., Voženílek, V. \& Tuček, P. (2016). Membership of Czech municipalities to rural and urban areas: a fuzzy-based approach. Geografie, 121 (1), 156-186.

Perlín, R., Kučerová, S. \& Kučera, Z. (2010). A typology of rural space in Czechia according to its potential for development. Geografie, 115(2), 161-187.

Porter, M. (1998). Clusters and the new economics of competition. Harvard Business Review, November-December, 77-90.

Prevenzer, M. (1997). The Dynamics of Industrial Clustering in Biotechnology. Small Business Economics, 8(2), 75-86.

Tushman, M., \& Anderson, P. (1986). Technological Discontinuities and Organizational Environments. Administrative Science Quarterly, 31, 439-465.

Venables, A.J. (1996). Localization of Industry and Trade Performance. Oxford Review of Economic Policy, 12(3), 52-60.

Wennberg, K., \& Lindquist, G. (2010). The effect of clusters on the survival and performance of new firms. Small Business Economics, 34(3), 221-241.

Wolfe, R.A. (1994). Organizational Innovation: Review, Critique and Suggested Research Directions. Journal of Management Studies, 31(3), 405-431. 